\title{
Como compor com um vírus!? Reflexões sobre os animal studies no tempo das pandemias
}

\section{How to compose with a virus!? Reflections on animal studies in pandemic times}

\author{
Eliane Sebeika Rapchan' \\ https://orcid.org/0000-0003-1605-9886 \\ esrapchan@gmail.com
}

Fagner Carniel"

https://orcid.org/0000-0002-7453-1993

fcarniel@uem.br

I Universidade de São Paulo - São Paulo, SP, Brasil

" Universidade Estadual de Maringá - Maringá, PR, Brasil 


\title{
Resumo
}

O que os animal studies teriam a nos ensinar sobre as catástrofes sanitárias de nossa geração? Este ensaio propõe que análises da pandemia provocada pela Covid-19 podem ser estimuladas pelas reflexões que a antropologia tem realizado ao longo das últimas décadas a respeito dos efeitos plurais do convívio entre animais humanos e não humanos. Relações tão íntimas e, por vezes, tão imprevisíveis com conjuntos de seres cuja agência e modos de existência nem sempre conseguimos identificar com precisão. A provocação é a de que a animalidade, enquanto um marcador relacional, não expressa somente o contraponto definido por alteridades interespecíficas que estabelecemos com certos animais diferentes de nós, mas configura-se como uma "categoria-metáfora" que nos habilita a perceber os múltiplos e complexos modos pelos quais compomos nossas vidas em relação à "natureza" de tudo aquilo que nos cerca.

Palavras-chave: animalidade; antropologia das relações humano-animais; Covid-19; pandemia.

\begin{abstract}
What does animal studies have to teach us about the health catastrophes of our generation? This essay proposes that analyzes of the pandemic caused by COVID-19 can be stimulated by the reflections that anthropology has carried out over the last decades regarding the plural effects of the interaction between human and non-human animals. Relationships so intimate and, at times, so unpredictable with sets of entities whose agency and modes of existence are not always able to identify precisely. The provocation is that animality, as a relational marker, not only expresses the counterpoint defined by interspecific alterities that we establish with certain animals different from us, but is configured as a "category-metaphor" that enables us to perceive the multiple and complex ways in which we compose our lives in relation to the "nature" of everything around us.
\end{abstract}

Keywords: animality; anthropology of human-animal relations; COVID-19; pandemic. 


\section{Apresentação}

A pandemia responsável pela doença que está assolando o planeta em 2020 e 2021, causada pela nova variação do coronavírus (Sars-CoV-2), parece ter começado a explicitar aspectos da organização de nossas sociedades e de nossas relações com tudo aquilo que consideramos não humanos que a tradição moderna-colonial tacitamente nos ensinou a ignorar (Rapchan; Carniel, 2020).

Por um lado, estamos aprendendo na própria pele que as políticas neoliberais, que geram fortunas e concentram renda, sustentam-se sobre um capitalismo financeiro que restringe ao mínimo a participação dos Estados nas áreas da saúde, moradia, alimentação, educação, trabalho, direitos civis (Stengers, 2015). As sociedades que conseguiram preservar minimamente instituições que assegurassem direitos e formas de bem viver a suas populações são as mesmas que têm conseguido se proteger relativamente do açoite da doença (Santos, 2020). Onde isso não foi feito, como é o caso do Brasil de Bolsonaro (Koury, 2020), escancaram-se profundas assimetrias e desigualdades sociais. O contágio desenfreado e suas consequências são uma expressão desses abismos sociais, revelando que as maiores vítimas da Covid-19, direta e indiretamente, são as mesmas cotidianamente atingidas pela miséria, pelo imperialismo, pelo racismo, pelo machismo, pelo capacitismo e pelas múltiplas formas de rebaixamento social.

Por outro lado, também parece estar se rotinizando certa compreensão de que o contágio pelo vírus, que provavelmente saltou de espécies silvestres, está relacionado com a acentuação das interações entre humanos e animais selvagens e com a superexploração de certas espécies domésticas, como porcos (Blanchette, 2020), gado bovino (Wallace, 2020) ou aves (Porter, 2019). Trata-se de mais uma expressão da invasão e devastação de ecossistemas que todas as recomendações científicas sobre os riscos associados ao desmatamento, ao aquecimento global e à extinção em massa não têm conseguido desacelerar (Latour, 2018). Em que pese a significativa redução dos índices de poluição decorrentes das medidas de isolamento social em alguns países, como a China (Cole; Elliott; Liu, 2020), a população mundial daqui em diante terá que aprender a lidar com muitas outras epidemias (Kelly; Keck; Lynteris, 2019) e, quem sabe, descobrir que a natureza também está em nós e se relacionar melhor com essa evidência (Rapchan; Carniel, 2016). 
No entanto, como poderíamos construir estratégias de coexistência com seres que simplesmente não enxergamos? Desde o estabelecimento da microbiologia moderna (Löwy, 2006), somos informados que os agentes infecciosos que nos causam tanto pavor possuem uma estrutura invisível aos olhos humanos e circulam pelo ambiente associando-se a outros organismos sem que possamos percebê-los - ao menos até a aparição dos primeiros sintomas. Talvez essa intangibilidade dos vírus possa explicar em parte as acusações contemporâneas de manipulação, a descrença em relação às recomendações sanitárias ou mesmo a insensibilidade diante dos efeitos sociais de uma pandemia. Entretanto, a invisibilidade desses "tipos diminutos de vida", para utilizar uma expressão empregada por Louis Pasteur no século XIX (Latour, 1999), não parece representar um mero problema de comunicação, mas a própria metáfora de que precisamos para imaginar horizontes de reexistência. Afinal, os cenários que enxergamos e pelos quais atualmente especulamos são restritamente limitados àquilo que podemos (ou queremos) considerar.

Neste ensaio, apresentamos uma reflexão a respeito de contribuições potenciais que a antropologia das relações humano-animais poderia oferecer aos estudos da pandemia provocada pela Covid-19. Para isso, mobilizamos repertórios teóricos e investigações empíricas acumuladas pela disciplina em diálogo com o campo dos animal studies para abordar as múltiplas e contraditórias relações que coletividades humanas assumidamente modernas estabeleceram com conjuntos heterogêneos de seres cuja agência e modos de existência nem sempre conseguimos identificar com precisão.

Portanto, nosso propósito é sugerir que a noção de "animalidade" não precisaria expressar apenas o contraponto definido por alteridades interespecíficas ou pelas relações que estabelecemos com certos animais diferentes de nós. Em vez disso, lançamos a hipótese de que podemos assumi-la como uma "categoria-metáfora" que comporta o potencial de revelar as múltiplas maneiras pelas quais compomos nossas vidas em relação à "natureza" de tudo aquilo que nos cerca - inclusive em relação ao novo coronavírus e à atual pandemia de Covid-19.

Quem sabe assim possamos compreender em profundidade o modo como nossos mundos foram e seguem sendo forjados a partir de relações plurais e contraditórias entre humanos diversos e naturezas mal conhecidas. O que, cá entre nós, talvez nos ajudasse a construir maneiras de lidar melhor com um 
futuro no qual, para o bem e para o mal, teremos que enfrentar os desafios postos pelo inevitável estreitamento das relações entre humanos e não humanos.

\section{Recompondo humanos e não humanos: contaminações antropológicas}

Ao imaginar aproximações possíveis entre os animais e a pandemia de Covid-19, talvez a "sopa de morcegos" ou o consumo de algum outro animal silvestre nos mercados úmidos de Wuhan sejam as únicas imagens que nos ocorram. No entanto, a tentativa duvidosa de se acusar certas coletividades por seus hábitos alimentares supostamente "exóticos" para, assim, localizar a origem da mutação desse agente infeccioso, como uma parcela significativa da mídia ocidental procurou realizar ao longo do último ano (Segata; Beck; Muccillo, 2020), certamente não representa uma contribuição significativa dos animal studies ao estudo de catástrofes sanitárias como esta que estamos vivenciando.

Dedicar nossa atenção às várias camadas de práticas e de significados implicadas na história das interações entre animais humanos e não humanos nos parece uma disposição muito mais produtiva para estimular análises antropológicas de eventos que estão provocando o que Bruno Latour (2017, p. 24) denominou recentemente de "uma profunda mutação em nossa relação com o mundo". Tais interações foram intensificadas no continuum moderno-colonial pelos violentos deslocamentos de populações europeias pela América, África e Ásia durante os processos de colonização ocorridos nos últimos cinco séculos. Assim, animais selvagens, habituados ou domesticados, seres microscópicos ou cosmológicos até então impensáveis começaram a fazer parte das narrativas sociais nos mais diversos contextos artísticos, técnicos, literários, filosóficos, bélicos, cosmológicos, ecológicos.

Mas nada disso representa exatamente uma novidade para a antropologia. Seja na tradição francesa de Mauss a Lévi-Strauss, seja na tradição anglo-saxã de Morgan a Evans-Pritchard e Bateson, ou ainda via a antropologia materialista de Harris, a perspectiva ecológica de Rappaport e as pesquisas em etnobiologia, aprendemos que a composição "humana" do social é sempre produzida em relação à coexistência de outros animais, bactérias, fungos, montanhas, plantas, rios. O que talvez seja novo neste momento em que nos encontramos 
não é a constatação empírica da presença de outros seres e de outros modos de coexistência multiespécie diferentes daqueles propalados pelo capitalismo agroindustrial (Kirksey; Helmreich, 2010), mas o adensamento contemporâneo das reflexões antropológicas sobre as relações entre humanos e não humanos. Um movimento intelectual que indica certo sentido de urgência na revisão dos parâmetros teórico-epistemológicos ocidentais que sustentam as análises dessas relações (Galvin, 2019).

Tal revisão parece sugerir ao menos duas consequências marcantes para o pensamento contemporâneo. A primeira impacta o modo de se produzir conhecimento, demonstrando a necessidade de assumirmos a consciência dos efeitos resultantes da intensificação de contatos entre espécies, da destruição de recursos não renováveis (Young et al., 2016) e dos resultados da ação humana sobre a vida e sobre o planeta (Moran, 2010). Para interpretar os efeitos sociológicos e culturais desses eventos sobre as estruturas biossociais, costumam ser mobilizadas categorias tão diversas como o antropoceno (Latour, 2018), a biopolítica (Foucault, 2008) ou o biocapital (Blanchette, 2015). O que tem sustentado críticas epistemológico-filosóficas dirigidas à ciência moderna que deságuam na crescente suspeita da validade explicativa dos dualismos por ela estabelecidos (Haraway, 1989) e sobre a capacidade do pensamento dito moderno de oferecer ideias para equacionar as relações entre humanos e não humanos (Latour, 1994; Lemm, 2013).

Um dos méritos desses movimentos é a ênfase na consciência de que os seres humanos não estabelecem relacionamentos apenas entre si, em termos sociais e simbólicos, mas também vivem profundamente conectados ao seu próprio corpo e ao mundo que esse corpo habita (Macnaghten; Urry, 2001), a outros seres vivos, bem como a artefatos (Appadurai, 1988), tecnologias (Haraway, 2015), recursos e lugares específicos (Janowski; Ingold, 2016).

A segunda diz respeito à oportunidade de repensarmos a singularidade humana. Critérios como bipedia, cérebro grande, uso de ferramentas, complexidade social e capacidade cognitiva, largamente utilizados para diferenciar humanos de outros seres vivos, desde a emergência da ciência moderna, têm-se mostrado insatisfatórios (Rapchan, 2019). Ao mesmo tempo, e diante da constatação de que todos os humanos estão em relação com outros seres, práticas como a domesticação de animais e de plantas, outrora consideradas exemplos da diligência humana, estão sendo observadas pela via das relações multiespécie (Kirksey; Helmreich, 2010). 
O que revela que tais processos também são relações de troca. São vias de contágio por patógenos, conexões com o "mundo selvagem" e com a oscilação entre a natureza e a cultura (Bennet, 2010). Aliás, há dúvidas de que a domesticação tenha ocorrido exclusivamente por ações humanas conscientes e sabe-se que tais processos estão fortemente relacionados com patogêneses, zoonoses e epidemias, tornando-se mais agudos em cenários de criação e confinamento em escala. Além disso, há fortes suspeitas de que a domesticação seja uma via de mão dupla, ou melhor, que ela transformou os humanos na mesma medida em que animais e plantas transformavam-se.

Nesse sentido, etnografias como a que Keck (2010) realizou junto aos vários atores envolvidos na criação de respostas à epidemia da gripe, desencadeada pelo vírus H1N1 na década passada, constituem apenas um entre tantos outros exemplos de contribuições antropológicas que podem auxiliar a compreender as habilidades de que dispomos para enfrentar as catástrofes ambientais e sanitárias que aterrorizam nossa geração e equacionar formas de a antropologia participar ativamente desse debate público. De acordo com Keck, o "mundo gripado" que emergiu em 2009 evidenciou a articulação que mantemos com algo que assumimos ser "externo" ao humano e que, paradoxalmente, está inevitavelmente associado a nós.

Contudo, o esforço de reconectar os laços que nos vinculam ao mundo em meio a uma pandemia exige que se ultrapasse o temor causado pelas perturbações que uma doença pode acarretar na constituição "natural" de nossos corpos biológicos. Parece ser preciso reaprender a problematizar o próprio modo pelo qual nos relacionamos com tudo aquilo que entendemos por "natureza" - em especial com os animais não humanos. O momento que vivemos é propício a esse exercício intelectual, pois permite aproveitar a mobilização social em torno de um vírus para construir instrumentos oblíquos que tornem visíveis o que nossa tradição científica muitas vezes invisibiliza: o fato de que partilhamos um mundo que não está desconectado de nós, mas que se compõe e se descompõe na pluralidade dos seres que o habitam.

Nesse caso, a pandemia de Covid-19 poderia ser encarada como mais uma manifestação contemporânea dos efeitos colaterais do projeto moderno-colonial. Ainda que as consequências desse surto para os sistemas públicos de saúde ao redor do planeta tenham provocado transformações dramáticas no modo como vivemos nossas vidas e ampliado as desigualdades sociais em uma escala assustadora, essa não foi a primeira vez que cepas de vírus até então 
desconhecidas saltaram de hospedeiros não humanos para contaminar populações humanas - e provavelmente não será a última.

A epidemia da Sars, ocorrida em 2002 e 2003, a pandemia da influenza H1N1, de 2009, o surgimento do coronavírus Mers, em 2014, e o surto de Ebola, entre 2014 e 2016, são exemplos recentes de agentes infecciosos que se originaram de transmissões zoonóticas e geraram doenças graves e mortais em grandes populações mundiais. Ao menos, esses microrganismos estão nos ensinando uma primeira lição: a consciência de que vivemos em coletivos formados por humanos e não humanos é vital para o nosso presente e para o nosso futuro (Auffrai et al., 2020).

Na década de 1980, a aparição da encefalopatia espongiforme bovina, popularmente conhecida como "doença da vaca louca", já havia nos alertado para a urgência de se fomentar o desenvolvimento de comunidades epistêmicas capazes de borrar as fronteiras entre o que se considera cultura e natureza e oferecer respostas adequadas à aceleração do surgimento de novos surtos precipitados por nossos próprios estilos de vida. O problema, como observa Segata (2020), é que quando um agente patogênico se espalha ele não carrega consigo apenas a probabilidade de causar doenças. Ele também favorece a composição de agendas contingentes que logram universalizar suas políticas de global health (Mol, 2008; Rajan, 2017) Nesse cruzamento de fronteiras e de escalas, se não conseguirmos construir alianças que nos permitam friccionar nossas diferenças e desigualdades por entre as lacunas deixadas pelas instáveis retóricas universalistas de nossa época, como analisa Tsing (2015), estaremos sujeitos a perpetuar os modos perversos que expressam a monocultura liberal e desenvolvimentista que nos trouxe até aqui.

Trata-se, portanto, de atender ao vibrante senso de urgência em produzirmos alternativas intelectuais e agendas políticas cada vez mais heterogêneas, mais articuladas, mas, ao mesmo tempo, cada vez menos concentradas na formulação de dispositivos biopolíticos globais de monitoramento e de controle dos seres vivos. Desse modo, talvez, seja possível vislumbrar o que Lévi-Strauss (2009) já chamou de "a lição de sabedoria das vacas loucas"; ou seja, a compreensão de que compartilhamos com outras espécies o desafio de termos de conviver com nossas semelhanças e diferenças para coexistir.

Todavia, combater as assimetrias que estruturam nossas relações com a natureza e com outros seres vivos para gerar novas experiências com o mundo 
nunca foi uma tarefa isenta de conflitos e controvérsias, pois implica reverter o desaparecimento de modelos locais de produção da natureza e dos ecossistemas. A exemplo do que argumenta Escobar (2005, p. 137), a preponderância do espaço global sobre o lugar, ou do universal sobre o particular, opera como um tipo de dispositivo de dominação profundo que moldou tanto o eurocentrismo quanto a condição moderno-colonial em que vivemos. Isso porque nossos marcos de referência para atuar no mundo, centrados em ontologias naturalistas e racionalistas, dificultam a compreensão de que os efeitos de fenômenos globais, como a recente pandemia provocada pela Covid-19, ativam desigualdades históricas. Portanto, remontam a legados indigestos e pouco debatidos do colonialismo que se expressam no presente e delineiam futuros nas mais diversas localidades do planeta.

Nesse sentido, gostaríamos de argumentar neste texto que a contiguidade entre animais humanos e não humanos, sejam eles autônomos ou dependentes, domesticados ou selvagens, literais ou ficcionais, suscita problemas antropológicos, ecológicos e políticos que possuem uma longa tradição no mundo moderno-colonial. Afinal, a pergunta pelo modo como poderemos nos relacionar com os vírus que circulam pelo planeta parece estar articulada com as maneiras através das quais temos nos relacionado com a diversidade de modos de vida no curso de nossas histórias. O que significa que a animalidade não expressaria exatamente a identidade de certos animais diferentes de nós, mas revela-se como um dos múltiplos marcadores que organizam o imaginário hegemônico de nossa época, moldado tanto pela influência do pensamento científico moderno quanto pela filosofia política e pela literatura colonial.

\section{Animal studies no futuro do pretérito, considerações finais}

Os animal studies recebem críticas constantes a respeito de suas dificuldades em analisar as diferentes facetas das relações de poder e as múltiplas desigualdades produzidas nas coletividades constituídas por humanos e outros animais. Tais provocações enfocam particularmente, mas não exclusivamente, os aspectos relativos ao estatuto ético ou jurídico de certos animais (Despret, 2016; Korsgaard, 2018; Lemm, 2013; Nussbaum, 2007; Wolfe, 2003), bem como os limites potenciais das proposições inspiradas pelo chamado "giro ontológico" 
e que se dedicam a composições multiespécie em ambientes isolados e descontextualizados (Bessire; Bond, 2014; Fischer, 2014; Holbraad; Pedersen, 2017).

De fato, a secundarização teórica e metodológica dos processos e dos dispositivos que tornam potencialmente "animalizáveis" todas as pessoas submetidas aos sistemas moderno-coloniais de dominação constitui um desafio central para o futuro dos estudos sobre as relações entre humanos e outros animais (Corbey; Theunissen, 1995; Galvin, 2019; Gruen, 2018; Kim, 2018; Marino, 2018; Tuck; Yang, 2012). Inclusive, retomando Ingold (1994), talvez seja possível afirmar que a classificação de seres nas categorias humanidade ou animalidade - que possibilitou a própria postulação dos animal studies e a de seus críticos - depende menos da "natureza" intrínseca dos seres, e das composições especiais que criamos com eles, do que da força e da regularidade dos atributos identitários que lhes conferem materialidade e inteligibilidade.

Portanto, entendemos que eventos como este que estamos vivenciando, desde a aparição do Sars-CoV-2 e do estabelecimento da pandemia de Covid-19, comportam certo potencial (reflexivo) de chamar a atenção de quem se dedica aos animal studies (Münster et al., 2021), em relação aos efeitos limitantes das retóricas disciplinares do "absolutamente animal" quando precisamos formular respostas significativas frente às consequências das relações com outros seres e aos efeitos da intrusão de conjuntos de seres e de relações que são muito mais plásticas do que nos habituamos a considerar. Por isso, sugerimos neste ensaio que a aproximação entre a antropologia e os animal studies, mediada pelo tipo de atravessamento que a noção de animalidade tem produzido entre os domínios da natureza e da sociedade, pode nos ajudar a assumir de uma vez por todas que os fundamentos das diferenças e desigualdades não se constituem exclusivamente entre humanos, mas também são sustentados pelas relações com outros seres vivos (Gruen, 2018), uma vez que ambas tendem a conectar-se e justificar-se mutuamente.

Esse quadro indica que a ênfase em perspectivas públicas e relacionais da antropologia das relações entre humanos e outros animais pode se somar aos avanços na defesa da reprodução da pluralidade e da diversidade em favor da resiliência frente às formas totalitárias de governo, de vida social e de produção de conhecimento (Latour, 2016; Tsing 2015). Ao mesmo tempo, o diagnóstico aponta ao menos dois caminhos possíveis diante dos imensos desafios colocados para a análise e a coconstrução de políticas ecológicas pautadas em 
princípios de cuidados, de direitos e de garantia de vida em contextos de vulnerabilidade (Münster et al., 2021).

O primeiro inclui a revisão do pensamento científico ocidental no que se refere às concepções homogeneizantes e dominantes sobre a natureza e sobre o lugar do humano no mundo, o que diz respeito tanto às biociências quanto às ciências sociais. Tal perspectiva, que, como outras semelhantes, nasceu sob forte influência de paradigmas inspirados nas hierarquias sociais do século XIX e no positivismo, insiste em descarnar os humanos de seus corpos e das relações com os não humanos, defende a legitimidade exclusiva das concepções ocidentais e teima em analisar os processos evolutivos como fenômenos independentes do próprio fluxo da vida (Oyama, 2000; Oyama; Griffiths; Gray, 2001).

O segundo aponta para a expectativa de efetivamente superarmos as hierarquias que colocam o conhecimento científico de inspiração moderno-colonial como a única forma legítima de saber e de agir no mundo, em detrimento de outras formas de viver e de produzir conhecimento e tecnologia. O reconhecimento da legitimidade desses saberes e a capacidade de promover alianças entre diferentes saberes podem nos poupar muitas perdas. É preciso, contudo, estarmos cientes que esse movimento é particularmente arriscado em tempos em que abundam teorias da conspiração e movimentos anticientíficos. Por isso, devemos entrar nos territórios movediços que constituem os mundos multiespecíficos para reunir subsídios que nos permitam reconhecer o que tem o potencial de nos destruir. Nessa direção, pesquisas etnográficas atreladas à reflexão antropológica podem ser aliadas valiosas.

Ao destacar esses caminhos, pretendemos frisar as contribuições que os animal studies estão oferecendo para a problematização do excepcionalismo humano. Através de conhecimentos e de práticas localmente situadas, que podem ou não estar globalmente articuladas, esses estudos apresentam outras camadas de complexidade às assimetrias do biopoder (Korsgaard, 2018), às complexidades atreladas aos princípios éticos e morais (Lemm, 2013) ou mesmo às lógicas contratuais que buscam homogeneizar e padronizar as participações de humanos e de outros seres vivos nas relações multiespecíficas (Nussbaum, 2007). Tais movimentos nos parecem favorecer aproximações e colaborações baseadas em situações específicas e pesquisas locais que articulam áreas de conhecimento e coletividades diversas de modo a produzir um conhecimento mais sensível, responsável e comprometido com todos os envolvidos, humanos e não humanos. 
Talvez esse seja o sentido de urgência que estamos tentando sinalizar. Afinal, como deveríamos estar aprendendo com as duras lições desta pandemia, o futuro da vida humana, de outras vidas não humanas e do planeta como o conhecemos parece depender disso (Danowski; Viveiros de Castro, 2014; Kolbert, 2014; Van Dooren, 2014). O problema comum dessa constatação se expressa na ânsia de produzir um tipo de conhecimento-poder que regule e homogeneíze o que é diverso de modo a torná-lo "controlável". Como argumenta Tsing (2015), o desejo de domesticar a natureza para controlar o social, tão recorrente nas histórias que o mundo euro-americano conta sobre si mesmo, converteu-se em uma espécie de "monocultura civilizacional". Isso submeteu violentamente as gerações que nos antecederam ao estabelecimento de fronteiras biopolíticas cada vez mais rígidas que visaram reestruturar territórios e modos de vida que, nos discursos de "seus representantes", a exemplo "dos nossos" (Stengers, 2015), autoproclamavam seus méritos na construção de um estado constante de "progresso" tecnológico e societário. As ilusões de controle absoluto da natureza, dos animais não humanos e dos humanos animalizados, alimentadas pelo extermínio, pela submissão ou pelos abusos cometidos contra animais, pessoas, territórios e recursos são postas em xeque todas as vezes em que uma zoonose vira uma epidemia.

A ficção científica frequentemente faz uso de um recurso literário que consiste em introduzir (ou retirar) uma única variável em determinado corpo social e analisar os impactos disso nas mais variadas dimensões: relações com a natureza, com o poder, com a velhice, entre gêneros, com o transcendente, com os oprimidos, com outros seres vivos, etc. Esse pequeno deslocamento e suas consequências profundas oferecem a oportunidade de realizar uma reflexão sobre o quanto o nosso mundo é complexo e interconectado.

Daí o sentido de nossa proposta: pensar a partir do vírus e compor com o vírus. O cenário constituído a partir da atual pandemia e os seus impactos estão associados à infecção global provocada por uma entidade microscópica. A introdução dessa pequena entidade-vírus associada ao seu caráter ambíguo e híbrido promoveu impactos que alteraram nossas vidas e que podem nos ajudar a refletir sobre o nosso mundo - afinal, estamos falando de um bicho, de uma proteína com agência ou de um ser vivo? O vírus não precisa ser encarado exclusivamente como um "inimigo" a se combater. Sua disseminação também nos ensina sobre nossos erros societários e evidencia conexões que insistimos 
em negligenciar, como as que se referem aos humanos, os outros animais, os lugares que habitamos e o planeta como um todo.

No caso da antropologia, nossa proposta se dirige à valorização das relações entre humanos e não humanos a partir de seus contextos vitais. O que significa, simultaneamente, abordar questões de poder e marginalidade frente ao capitalismo e à globalização, tomar humanos e não humanos como espécies companheiras e encarar a possibilidade de a antropologia abordar o mundo vivido, sem apartá-lo da política e da história.

\section{Referências}

APPADURAI, A. (ed.) The social life of things. Cambridge: Cambridge University Press, 1988.

AUFFRAI, C. et al. COVID-19 and beyond: a call for action and audacious solidarity to all the citizens and nations, it is humanity's fight. In: SSRN. Rochester: SSRN, 25 June 2020. Disponível em: https://papers.ssrn.com/sol3/papers.cfm?abstract_ $\mathrm{id}=3630412$. Acesso em: 10 ago. 2020.

BENNET, J. Vibrant matter: a political ecology of things. Durham: Duke University Press, 2010.

BESSIRE, L.; BOND, D. Ontological anthropology and the deferral of critique. American Ethnologist, Washington, DC, v. 3, n. 41, p. 440-456, Aug. 2014.

BLANCHETTE, A. Herding species: biosecurity, posthuman labor, and the American industrial pig. Cultural Anthropology, Arlington, v. 30, n. 4, p. 640-669, Nov. 2015.

BLANCHETTE, A. Porkopolis: American animality, standardized life, and the factory farm. Durham: Duke University Press, 2020.

COLE, M., ELLIOTT, R.; LIU, B. The impact of the Wuhan Covid-19 lockdown on air pollution and health: a machine learning and augmented synthetic control approach. Birmingham: University of Birmingham, 2020.

CORBEY, R.; THEUNISSEN, B. (ed.). Ape, man, apeman: changing views, 1600-2000. Leiden: Royal Netherlands Academy of Arts and Sciences, 1995.

DANOWSKI, D.; VIVEIROS DE CASTRO, E. Há mundo por vir?: ensaio sobre os medos e os fins. Florianópolis: Desterro, Cultura e Barbárie, 2014. 
DESPRET, V. What would animals say, if we asked the right questions?. Minneapolis: University of Minnesota Press, 2016.

ESCOBAR, A. O lugar da natureza e a natureza do lugar: globalização ou pós-desenvolvimento?. In: LANDER, E. (org.). A colonialidade do saber: eurocentrismo e ciências sociais: perspectivas latino-americanas. Buenos Aires: Clacso, 2005. p. 69-86.

FISCHER, M. M. J. The lightness of existence and the origami of "French" anthropology: Latour, Descola, Viveiros de Castro, Meillassoux, and their so-called ontological turn. HAU, Chicago, v. 1, n. 4, p. 331-355, Summer 2014.

FOUCAULT, M. Segurança, território, população: curso dado no Collège de France (1977-1978). São Paulo: Martins Fontes, 2008.

GALVIN, S. S. Interspecies relations and agrarian worlds. Annual Review of Anthropology, Palo Alto, v. 47, p. 233-249, Oct. 2019.

GRUEN, L. Introduction. In: GRUEN, L. (ed.). Critical terms for animal studies. Chicago: The University of Chicago Press, 2018. p. 1-14.

HARAWAY, D. Primate visions: gender, race, and nature in the world of modern science. New York: Routledge, 1989.

HARAWAY, D. Anthropocene, Capitalocene, Plantationocene, Chthulucene: making kin. Environmental Humanities, Durham, v. 6, n. 1, p. 159-165, May 2015.

HOLBRAAD, M.; PEDERSEN, M. A. The ontological turn: an anthropological exposition. Cambridge: Cambridge University Press, 2017.

INGOLD, T. Humanity and animality. In: INGOLD, T. (ed.). Companion encyclopedia of anthropology. London: Routledge, 1994. p. 14-32.

JANOWSKI, M.; INGOLD, T. (ed.). Imagining landscapes: past, present and future. New York: Routledge, 2016.

KECK, F. Un monde grippé. Paris: Flammarion, 2010.

KELLY, A. H.; KECK, F.; LYNTERIS, C. (ed.). The anthropology of epidemics. London: Routledge, 2019.

KIM, C. J. Abolition. In: GRUEN, L. (ed.). Critical terms for animal studies. Chicago: The University of Chicago Press, 2018. p. 15-35.

KIRKSEY, S. E.; HELMREICH, S. The emergence of multispecies ethnography. Cultural Anthropology, Arlington, v. 25, n. 4, p. 545-576, Oct. 2010. 
KORSGAARD, C. M. Fellow creatures: our obligations to the other animals. Oxford: Oxford University Press, 2018.

KOLBERT, E. The sixth extinction: an unnatural history. New York: Henry Holt, 2014.

KOURY, M. G. P. Antropologia e situações-limites: neoliberalismo e pandemia. Dilemas, Rio de Janeiro, n. esp., p. 1-8, jun. 2020.

LATOUR, B. Jamais fomos modernos: ensaio de antropologia simétrica. Rio de Janeiro: Editora 34, 1994.

LATOUR, B. Pandora's hope: essays on the reality of science studies. Cambridge: Harvard University Press, 1999.

LATOUR, G. Foreword: the scientific fables of an empirical La Fontaine. In: DESPRET, V. What would animals say, if we asked the right questions?. Minneapolis: University of Minnesota Press, 2016. p. vii-xiv.

LATOUR, B. Facing Gaia: eight lectures on the new climate regime. Cambridge: Polity Press, 2017.

LATOUR, B. Down to earth: politics in the new climatic regime. Cambridge: Polity Press, 2018.

LEMM, V. Nietzsche y el pensamiento político contemporáneo. Santiago: Fondo de Cultura Económica, 2013.

LÉVI-STRAUSS, C. A lição de sabedoria das vacas loucas. Estudos Avançados, São Paulo, v. 23, n. 67, p. 211-216, 2009.

LÖWY, I. Vírus, mosquitos e modernidade: a febre amarela no Brasil entre ciência e política. Rio de Janeiro: Editora Fiocruz, 2006.

MACNAGHTEN, P.; URRY, J. (ed.). Bodies of nature. London: Sage Publications, 2001.

MARINO, L. Captivity. In: GRUEN, L. (ed.). Critical terms for animal studies. Chicago: The University of Chicago Press, 2018. p. 106-120.

MOL, A. The logic of care: health and the problem of patient choice. New York: Routledge, 2008.

MORAN, E. F. Adaptabilidade humana: uma introdução à antropologia ecológica. São Paulo: Edusp, 2010. 
MÜNSTER, U. et al. Multispecies care in the sixth extinction. In: FIELDSIGHTS. [S. l.]: Society for Cultural Anthropology, 26 Jan. 2021. Disponível em: https://culanth.org/ fieldsights/series/multispecies-care-in-the-sixth-extinction. Acesso em: 27 jan. 2021.

NUSSBAUM, M. Frontiers of justice. Cambridge: Harvard University Press, 2007.

OYAMA, S. Evolution's eye: a systems view of the biology-culture divide. Durham: Duke University Press, 2000.

OYAMA, S.; GRIFFITHS, P. E.; GRAY, R. D. Cycles of contingency. London: A Bradford Book, 2001.

PORTER, N. Viral economies: bird flu experiments in Vietnam. Chicago: The University of Chicago Press, 2019.

RAJAN, K. S. Pharmocracy: value, politics, and knowledge in global biomedicine. Durham: Duke University Press, 2017.

RAPCHAN, E. S. Somos todos primatas: e o que a antropologia tem a ver com isso?. Curitiba: Appris, 2019.

RAPCHAN, E. S.; CARNIEL, F. Natureza ou cultura na formação escolar brasileira. Inter-Legere, Natal, v. 1, n. 18, p. 76-94, 17 nov. 2016.

RAPCHAN, E. S.; CARNIEL, F. Desigualdades entrelaçadas: figurações da animalidade no imaginário colonial-moderno. Revista Latinoamericana de Estudios Críticos Animales, Buenos Aires, v. 2, n. 7, p. 278-303, dez. 2020.

SANTOS, B. de S. A cruel pedagogia do vírus. São Paulo: Boitempo, 2020. (Pandemia Capital).

SEGATA, J. Covid-19, biossegurança e antropologia. Horizontes Antropológicos, Porto Alegre, ano 26, n. 57, p. 275-313, maio/ago. 2020.

SEGATA, J.; BECK, L.; MUCCILLO, L. A Covid-19 e o capitalismo na carne. Tessituras, Pelotas, v. 8, n. 1, p. 355-373, jan. 2020.

STENGERS, I. No tempo das catástrofes: como resistir à barbárie que se aproxima. São Paulo: Cosac Naify, 2015.

TSING, A. The mushroom at the end of the world: on the possibility of life in capitalist ruins. Princeton: Princeton University Press, 2015.

TUCK, E.; YANG, K. W. Decolonization is not a metaphor. Decolonization: Indigeneity, Education \& Society, Toronto, v. 1, n. 1, p. 1-40, Sep. 2012. 
VAN DOOREN, T. Flight ways: life and loss at the edge of extinction. New York: Columbia University Press, 2014.

WALLACE, R. A pandemia e o agronegócio: doenças infecciosas, capitalismo e ciência. São Paulo: Elefante: Igrá Kniga, 2020.

WOLFE, C. (ed.). Geontologies: the question of the animal. Minneapolis: University of Minnesota Press, 2003.

YOUNG, H. S. et al. Patterns, causes, and consequences of anthropocene defaunation. Annual Review of Ecology, Evolution, and Systematics, Palo Alto, v. 47, p. 333-358, Nov. 2016.

Recebido: 12/08/2020 Aceito: 20/01/2021 | Received: 8/12/2020 Accepted: 1/20/2021 